\title{
Effect of medication withdrawal on pain in Parkinson's disease patients - an observational study based on a sample of patients without antiparkinsonian medications
}

\author{
Rosimary Amorim Lopes ${ }^{1}$ (D) , José Oswaldo de Oliveira Júnior ${ }^{2 *}$ (D), \\ Fabio Henrique de Gobbi Porto ${ }^{3}$ (D), Ricardo Vieira Botelho ${ }^{1}$
}

\section{SUMMARY}

OBJECTIVES: To assess the effect of withdrawal of the antiparkinsonian drug regimen administration on patients with PD and its relation to pain.

METHODS: The sample included 22 men and 12 women who were candidates for neurosurgery to control motor signs and symptoms treated with L-dopa as a drug, alone or in combination with others (Cholinergic Antagonists; Dopamine Agents). All of them were examined at two different moments, with and without medication, and analyzed for painful symptoms. The Hoehn and Yahr scale was used for functional staging of the disease. Pain intensity was assessed by using the numerical verbal scale.

RESULTS: The mean pain intensity among those on medication $\{2.17 \pm 0.39$ (SE)\} was significantly lower than in the abstinence group $\{4.2 \pm 0.59$ (SE), $p=0.006$, Wilcoxon\}, which corresponded to the increase in the total functional staging score from 93 to 111 , respectively. CONCLUSION: The interruption of the administration of specific medications in patients with Parkinson's disease caused, or increased the intensity of, painful discomfort correlated with the intensity of functional impairment. This effect was also observed in women, but it was statistically relevant only for men. The results suggest that pain may be a "red flag" that points to the need for a therapeutic drug review when its presence or worsening is detected.

KEYWORDS: Pain. Parkinson's disease. Levodopa. Cholinergic Antagonists. Dopamine Agents. Drug Therapy.

\section{INTRODUCTION}

Background/rationale: Parkinson's disease (PD) is an idiopathic, degenerative disease characterized by the progressive loss of dopaminergic neurons. Dopamine is a catecholamine neurotransmitter that acts as a therapeutic target in the disease ${ }^{1}$. Parkinson's disease is an incurable condition, and any treatment is still symptomatic. The discomfort of the disease is greatly increased when associated with pain ${ }^{1}$. In this scenario, part of the pain is directly related to the clinical control of the disease, but the literature is quite poor as to the actual measurement of this involvement. The additional use of analgesics for antiparkinsonian polypharmacy increases the risks of adverse effects in an already vulnerable population. The treatment, although not curative, is very useful, as it allows the restoration of the dopaminergic function and of the patient's quality of life for many years. However, disease progression may make it

\footnotetext{
'Instituto de Assistência Médica do Servidor Público Estadual, Programa de Pós-Graduação em Ciências da Saúde - São Paulo (SP), Brasil. ${ }^{2}$ Antônio Cândido de Camargo Cancer Center, Departamento Central da Dor e Estereotaxia - São Paulo (SP), Brasil.

${ }^{3}$ Hospital Brigadeiro, Unidade de neurocirurgia de distúrbios do movimento - São Paulo (SP), Brasil

Corresponding author: jo.oliveiraj@@gmail.com.br

Conflicts of interest: the authors declare there is no conflicts of interest. Funding: none

Received on December 07, 2020. Accepted on December 13, 2020.
} 
increasingly difficult to control the symptoms ${ }^{2}$. In some cases, surgical treatment may be offered as an adjunctive therapeutic option to clinical treatment ${ }^{3}$.

For surgical treatment, patients are submitted to preoperative test screening in order to predict the possibility of postoperative improvement. In one of the test phases, the patient is evaluated in on and off states. The standardized on state for the exam occurs when the patient has the best motor performance related to the effect of the drug regimen. In the off state, the patient should be off the drug regimen (withdrawal) for at least 12 hours 4 .

Pain and sensory dysfunctions are symptoms reported by patients with parkinsonian syndrome and may precede or accompany motor symptoms. Sensory dysfunctions are described as numbness, tingling, burning sensation, cold and heat ${ }^{5}$. Dopaminergic deficit in PD patients may lead to pain ${ }^{6}$. The pain symptom is present in more than one third of the patients ${ }^{7}$.

Objectives: To evaluate the effect of the drug regimen withdrawal in PD patients and its relation to pain.

\section{METHODS}

The survey was conducted from April 2018 to August 2019.

\section{Study design}

This is a case control in which the same sample of patients will be evaluated in a cross-sectional design in two stages of the disease: under medication and with medication withdrawal.

\section{Setting}

To evaluate the effect of the drug regimen withdrawal in PD patients, a sample of candidates for surgery was studied. Standardized testing was performed on these patients to assess the effect of medication on symptomatology.

\section{Ethical aspects}

The project was submitted for evaluation by the Ethics Committee and approved in both institutions under numbers 3,331,470 (Hospital Brigadeiro UGA V-SP) and 3,467,182 (Instituto de Assistência Médica ao Servidor Público Estadual de São Paulo).

\section{Sample origin}

The sample was selected from 600 patients referred for possible surgery and was composed of 34 patients, 22 male and 12 female individuals. The sample was composed by a convenience sample and all patients in the described period of time were studied.

PD patients from the São Paulo State Health Network were referred to two institutions specialized in the surgical treatment of PD. Six hundred patients sought care during the study period. Among the candidates for surgery, thirty-four patients met the inclusion and exclusion criteria and were invited for the research. Everyone consented to participate.

\section{Participants - Inclusion criteria}

The patients eligible for the research were the candidates for functional neurosurgery to control the motor symptoms of Parkinson's disease, who had been diagnosed for at least 4 years and used 1-dopa in the pharmacological treatment.

\section{Exclusion criteria}

Patients who had had the disease for less than 4 years, those who did not use 1-dopa in their pharmacological treatment, and the ones with other neurological diseases, such as brain tumor, depression, drug addiction and/or active alcoholism, were excluded.

The patients were evaluated in two moments: first they were evaluated in the on state (under the effect of the drug treatment), and then they were reassessed in the off state (with the pharmacological treatment suspended for 24 hours). Between the two moments, the percentage of symptoms worsening without medication was estimated.

\section{Data sources/measurement: the variables studied were}

Demographic variables: age and gender. Time of diagnosis of the disease. Stage of the disease. Drugs in use.

\section{Quantitative variables}

Pain intensity: pain was assessed by using the numerical verbal scale (NVS) ${ }^{8}$.

The Hoehn and Yahr scale (HYS) was used for the functional staging of the disease. (Table 1$)^{9}$.

\section{Statistical methods}

Data were compiled into a database and analyzed using the IBM SPSS software (version 25.0). Frequency descriptions in absolute numbers and percentage rates $(\mathrm{N}$ and \%) were presented for qualitative variables, and measures such as mean, median and standard deviation for quantitative variables according to normal distribution.

The normal distribution of the variables was tested with the Shapiro-Wilk test. The Wilcoxon test was applied to data without normal distribution.

The Spearman's correlation was calculated to evaluate any possible correlation between pain intensity, time since diagnosis and the age of patients, The comparison related to the stage of the disease in the on and off periods was performed with the Chi-square test. In all tests, a significance level of $5 \%$ was set. 
To estimate the effect of age and disease duration as confounding factors, a correlation (Spearman) was made between the age and the pain scale in on and off stages.

The distribution of pain scales in both sexes in on and off stages was compared.

\section{RESULTS}

\section{Demographic and clinical results}

\section{Case-control study: participants}

Their mean age was $58.38 \pm 7.9$ years.

The average time since diagnosis was $9.8 \pm 3.30$ years.

Drug treatment in use: only one patient $(2.9 \%)$ used l-dopa alone, and 33 patients (97.1\%) used 1-dopa associated to other medications, according to their doctor's criteria (pramipexol, entacapone, triexiphenidyl, amantadine, rotigotine, selegiline and/or akineton).

Staging of the disease was assessed under the effect of the pharmacological treatment (on) and without the effect of drugs (off) (Table 2).

\section{Percentage of patients in the functional stages of the disease in the on and off periods}

There were no patients with unilateral involvement (stage 1). At stage 1.5 , there were two patients on and two off. In the on phase, there was no patient in stage 5 (bed or wheelchair). However, in the off period, $11.8 \%$ of the patients progressed to this stage (stage 5). There was a higher distribution of critically ill patients in the off group as compared to the on group $\left(\chi^{2}\right.$ test, $\left.\mathrm{p}<0.002\right)$ (Figure 1$)$.

\section{Effect of drug administration discontinuation on the functional stages of the disease}

The use of medication altered the distribution of functional stages. In the off-state evaluation, symptoms worsened in most cases (Figure 2).
Table 2. Sociodemographic and clinical data.

\begin{tabular}{|c|c|c|}
\hline Variables & $\mathrm{n}$ & Mean \\
\hline Age & 34 & $58.38( \pm 7.966)$ \\
\hline Time from onset & 34 & $9.79( \pm 3.301)$ \\
\hline Gender & $\mathrm{n}$ & $\%$ \\
\hline Male & 22 & 64.7 \\
\hline Female & 12 & 35.3 \\
\hline Medication & $\mathrm{n}$ & $\%$ \\
\hline L-dopa alone & 1 & 2.9 \\
\hline $\begin{array}{l}\text { Full antiparkinson } \\
\text { pharmacotherapy }\end{array}$ & 33 & 97.1 \\
\hline Hoern e Yahr - on(8) & $\mathrm{n}$ & $\%$ \\
\hline 1.5 & 2 & 5.9 \\
\hline 2.0 & 5 & 14.7 \\
\hline 2.5 & 12 & 35.3 \\
\hline 3.0 & 10 & 29.4 \\
\hline 4.0 & 5 & 14.7 \\
\hline Total & 34 & 100.0 \\
\hline Hoern and Yahr - off & $\mathrm{n}$ & $\%$ \\
\hline 1.5 & 2 & 5.9 \\
\hline 2.0 & 1 & 2.9 \\
\hline 2.5 & 6 & 17.6 \\
\hline 3.0 & 13 & 38.2 \\
\hline 4.0 & 8 & 23.5 \\
\hline 5.0 & 4 & 11.8 \\
\hline Total & 34 & 100.0 \\
\hline
\end{tabular}

The table shows the distribution of the average age and time since the diagnosis of the disease, of gender, the drug regimen, and functional stage of the disease in effect (on) and without (off) the medication.

Table 1. Modified Hoehn \& Yahr scale based on Schenkman, et al. ${ }^{9}$.

\begin{tabular}{l|c}
\hline Stage 0 & No signs of disease \\
\hline Stage 1 & Unilateral disease Stage \\
\hline Stage 1.5 & Unilateral plus axial involvement Stage \\
\hline Stage 2 & Bilateral disease, without impairment of balance \\
\hline Stage 2.5 & Mild bilateral disease; recovery on pull test \\
\hline Stage 3 & Mild to moderate bilateral disease; some postural instability; capacity for living independent lives \\
\hline Stage 4 & Severe disability; still able to walk or stand unassisted \\
\hline Stage 5 & Wheelchair bound or bedridden unless aided \\
\hline
\end{tabular}

In this scale, intermediate stages were added between the first and second and between the second and third to better represent the progression of patients' functional worsening. 


\section{Effect/lack of drug on pain}

\section{Pain intensity}

A painful discomfort was detected in the majority of patients examined (between 60 and 70\%). The mean pain intensity in patients treated with medication was significantly lower than in the off group, $2.17 \pm 0.39$ (SE) versus $4.2 \pm 0.59$ (SE), $\mathrm{p}=0.006$, Wilcoxon (Figure 2).

\section{Bias - Control of results according to age, sex and time of disease}

To estimate the effect of age and disease duration as confounding factors, which could influence the results, the following separate analyses were performed for age, sex and duration of the disease.

- Age: Spearman's correlation was carried out between the age and the pain scale in on and off stages. There was no significant correlation between age and pain scales in the on $(\mathrm{p}=0.63)$ and off $(\mathrm{p}=0.75)$ stages.

- Gender: the distribution of pain scales in both sexes in on and off stages was compared. In male individuals, the pain scale was significantly lower in the on stage (1.91 $\times 4.27, \mathrm{p}=0.008)$. In females, there was no significant difference $(2.67 \times 4.08, \mathrm{p}=0.22)$. However, the number of women studied was too small to reveal any difference $(n=12)$.

- Time from onset: For this analysis, the time since diagnosis was used for greater accuracy. A correlation test was performed between the time of diagnosis and the EVN scale values at both stages. There was no correlation between the time since diagnosis and the EVN scale in the on or off period ( $\mathrm{p}=0.15$ and 0.80 , respectively).

\section{DISCUSSION}

Key results: the results of this study showed that pain intensity in patients who are not treated with 1-dopa increased when compared to treated patients $(\mathrm{p}=0.006)$. Another study reached the same result ${ }^{10}$.

This modified $\mathrm{H}$ and $\mathrm{Y}$ scale was used to assess and grade the functional impairment of Parkinson's disease. Among its main advantages, it is simple and easy to apply. It captures typical patterns of progressive motor impairment, and can be applied regardless of whether or not patients are receiving dopaminergic therapy. Progression in the possible six stages in the scale is correlated with motor decline, deterioration in

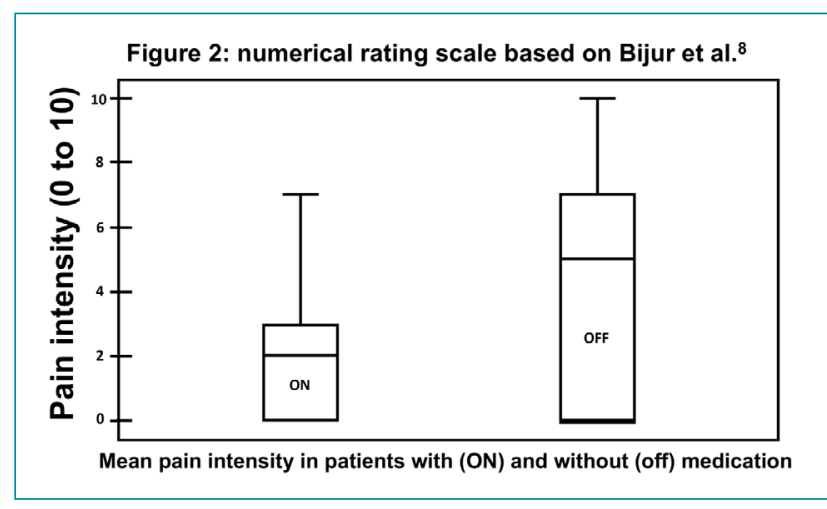

Figure 2. Numerical rating scale based on Bijur et al. ${ }^{8}$.

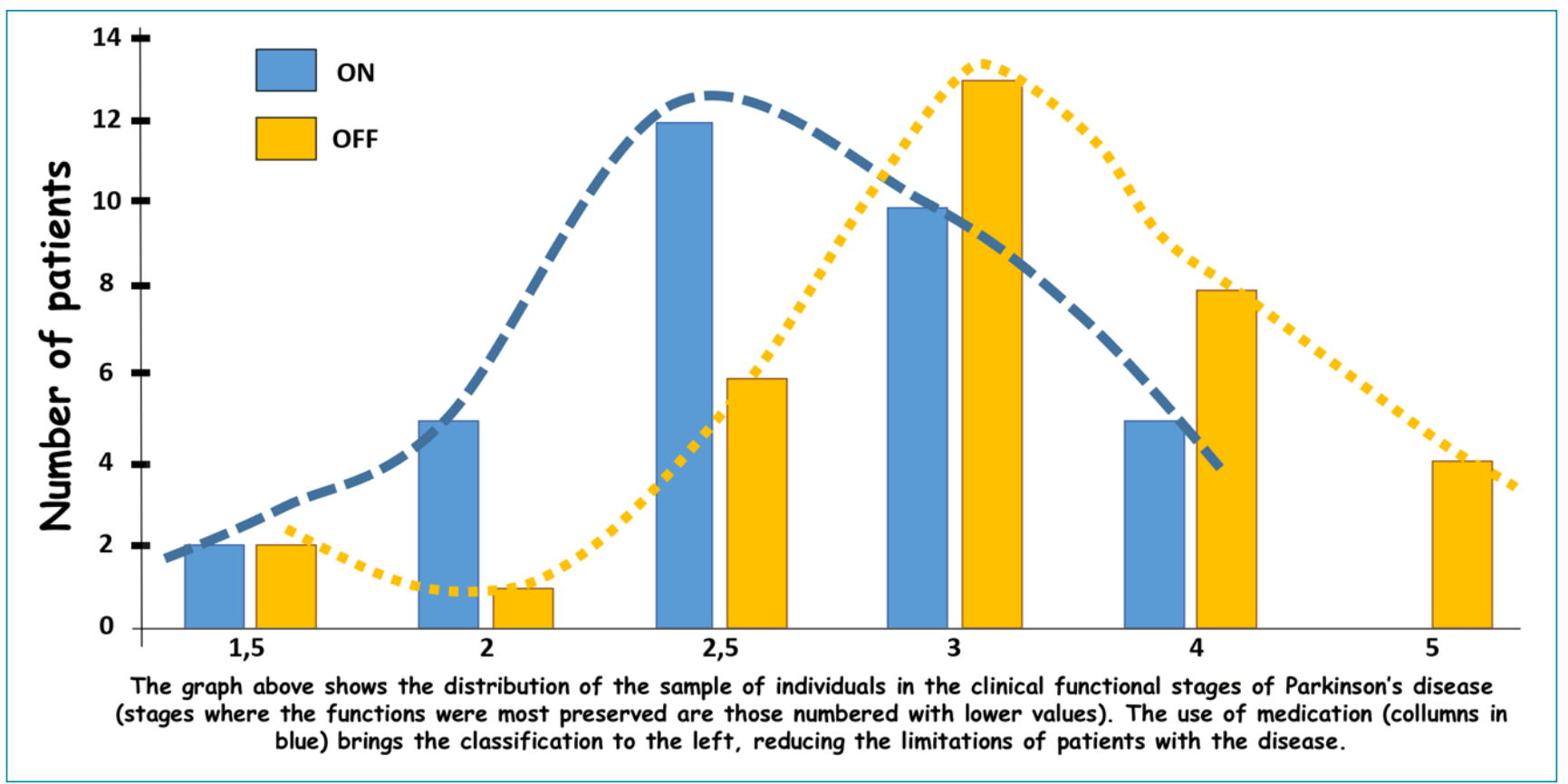

Figure 1. Modified Hoehn \& Yahr scale basead on Schenkman et al. ${ }^{9}$. 
quality of life and neuroimaging studies on dopaminergic loss. The interruption of drug administration caused an increase in the total functional staging score, from 93 to 111 , respectively.

There was no influence of time since diagnosis or age in the results. The number of women affected was very small for any conclusion, but the intensity of pain in the off stage was stronger in male individuals. The suppression of l-Dopa increased the number of severely affected patients.

The most common PD-related painful syndromes are musculoskeletal (50\%), followed by dystonia (21.4\%), root (10.7\%), articular (7.1\%), headache (7.1\%) and nonspecific syndromes $(2.6 \%)^{11}$. Some other types of pain may be present in PD patients, but may not be related to symptoms specifically caused by PD. Studies associate pain in PD patients with motor symptoms, stiffness, tremor and dyskinesia ${ }^{10}$.

Stiffness has been considered as a determining factor in pain, but not tremor and bradykinesia ${ }^{11}$.

In a published series assessing pain and $\mathrm{PD}$, pain intensity was described as moderate and severe in $84 \%$ of the cases ${ }^{12,13}$.

In some studies, pain prevailed on the initially affected side of the body stricken by PD, and became worse when there was greater motor impairment, suggesting a relation between pain and disease or dopamine depletion.

In patients with $\mathrm{PD}$, dopaminergic decline may change sensory thresholds. Although the antinociceptive and modulatory effect of pain is not yet fully understood, the introduction of l-dopa in these patients may improve both motor and sensory abnormalities ${ }^{6}$.

The hypothalamic nucleus would provide dopamine-mediated inhibitory projections for nociceptive transmission in the spinal cord, controlling pain by supraspinal portions ${ }^{14}$.

In a review of the pathophysiology of central pain, Kumar et al. show specific inhibited or sensitized neuronal populations in the cortical and subcortical regions, associated with lesions or changes in thalamic nuclei ${ }^{15}$. In PD, hyperactivity of the internal pale globe intensely inhibits the various thalamic nuclei and may produce a similar scenario to that found in central pain. Also, catecholamines in the central nervous system may have a sedative and analgesic effect ${ }^{16}$.

Hyperkinetic signs and symptoms, such as tremors or dyskinesia, may be associated with complaints of pain. Our results point to the onset or worsening of pain when the drug is interrupted, including, at least in part, those with tremors. The inverse situation was observed in patients with induced dyskinesia.

Induced dyskinesia may lead to the overload of the musculoskeletal system that transcends the possible central analgesic effects of partial dopaminergic hyperfunction and may be associated with painful discomfort. The discontinuation of the medication regimen may attenuate the reported pain. One of the evaluated patients reported a reduction in pain intensity by half during the medication withdrawal period, which progressed without dyskinesia.

\section{Limitations}

The sample size used in this study was small and needs to be increased, and a more detailed assessment with classification of the type of pain and its relation to each nuance of the different clinical conditions deserves to be carried out.

\section{Interpretation}

The discontinuation of drug administration in patients with Parkinson's disease increased pain intensity, correlated with the intensity of the patients' functional impairment. The confirmation of worse painful discomfort in the period following the interruption of specific antiparkinsonian medication can enhance and promote greater motivation for a better clinical control of patients. The results suggest that pain may be a clinical warning that points to the need for a therapeutic drug review when its presence or worsening is detected.

\section{Generalisability}

This effect was evident in male patients and cannot be proven in female patients. The time since diagnosis of the disease did not influence the results. Although the results obtained in this work should be tested in other samples, it is suggested that patients with PD and pain should be evaluated if they are in their best medication control.

\section{Funding}

There was no external funding other than that supported by the authors.

\section{ACKNOWLEDGMENTS}

We would like to thank the statistician Vinicius Calsavara for his assistance with the statistic evaluation of this paper. Vinicius has no conflict of interest to be declared and provided no financial support in relation to this manuscript.

\section{AUTHORS" CONTRIBUTIONS}

All authors, JOOJ e RVB had full access to all the data in the study and are responsible for the integrity of the data and the accuracy of data analysis. RAL and FGP designed the study protocol. RAL and RVB carried out the literature searches and summaries of previous related work and wrote the first draft of the manuscript. JOOJ and RVB revised the intellectual content and provided the final approval of the manuscript. 


\section{REFERENCES}

1. Alves G, Forsaa EB, Pedersen KF, Dreetz Gjerstad M, Larsen JP. Epidemiology of Parkinson's disease. J Neurol. 2008;255(Suppl 5):18-32. https://doi.org/10.1007/s00415-008-5004-3

2. Scherbaum R, Hartelt E, Kinkel M, Gold R, Muhlack S, Tönges L. Parkinson's disease multimodal complex treatment improves motor symptoms, depression and quality of life. J Neurol. 2020;267(4):954-65. https://doi.org/10.1007/s00415-01909657-7

3. Krack P, Volkmann J, Tinkhauser G, Deuschl G. Deep brain stimulation in movement disorders: from experimental surgery to evidence-based therapy. Mov Disord. 2019;34(12):1795810. https://doi.org/10.1002/mds.27860

4. Pinto RASR, Borges V, Aguiar PMC, Ferraz FAP, Hisatugo MKI, Ferraz HB. Avaliação das atividades da vida diária dos pacientes com doença de Parkinson submetidos a cirurgia estereotáxica. Arq Neuropsiquiatr. 2002;60(2-B):435-41. PMID: 12131946

5. Ford B. Pain in Parkinson's disease. Mov Disord. 2010;25(Suppl 1):S98-103. https://doi.org/10.1002/mds.22716

6. Cury RG, Galhardoni R, Fonoff ET, Lloret SP, Ghilardi MGS, Barbosa ER, et al. Sensory abnormalities and pain in Parkinson disease and its modulation by treatment of motor symptoms. Eur J Pain. 2016;20(2):151-65. https://doi.org/10.1002/ejp.745

7. Fil A, Cano-de-la-Cuerda R, Muñoz-Hellín E, Vela L, Ramiro-González M, Fernández-de-las-Peñas C. Pain in Parkinson disease: a review of the literature. Parkinsonism Relat Disord. 2013;19(3):285-94. https://doi.org/10.1016/j. parkreldis.2012.11.009

8. Bijur PE, Latimer CT, Gallagher EJ. Validation of a verbally administered numerical rating scale of acute pain for use in the emergency department. Acad Emerg Med. 2003;10(4):390-2. https://doi.org/10.1111/j.1553-2712.2003.tb01355.x
9. Schenkman ML, Clark K, Xie T, Kuchibhatla M, Shinberg M, Ray L. Spinal movement and performance of a standing reach task in participants with and without Parkinson disease. Phys Ther. 2001;81(8):1400-11. https://doi.org/10.1093/ptj/81.8.1400

10. Ford B. Pain in Parkinson's disease. Mov Disord. 2010;25(Suppl 1):S98-103. https://doi.org/10.1002/mds.22716

11. Silva EG, Viana MA, Quagliato EM. Pain in Parkinson's disease: analysis of 50 cases in a clinic of movement disorders. Arq Neuropsiquiatr. 2008;66(1):26-9. https://doi.org/10.1590/ s0004-282x2008000100007

12. Coriolano MGWS, Balbino JMS, Silva BRV, Cabral ED, Asano $A G$, Lins $O G$, et al. Pain characterization in patients with Parkinson's disease. Rev Dor. 2014;15(2):78-82. https://doi. org/10.5935/1806-0013.20140019

13. Scalzo PL, Santos RMS, Carvalho DV, Magalhães HC, Christo PP, Souza MS, et al. Pain characterization of Parkinson's disease patients. Rev Bras Neurol. [online] 2018 [cited on October, 2018];54(4):19-25. Available from: https://docs.bvsalud.org/ biblioref/2018/12/967831/revista544v20-artigo-3.pdf

14. Scott DJ, Heitzeg MM, Koeppe RA, Stohler CS, Zubieta JK. Variations in the human pain stress experience mediated by ventral and dorsal basal ganglia dopamine activity. J Neurosci. 2006;26(42):10789-95. https://doi.org/10.1523/ JNEUROSCI.2577-06.2006

15. Kumar B, Kalita J, Kumar G, Misra UK. Central poststroke pain: a review of pathophysiology and treatment. Anesth Analg. 2009;108(5):1645-57. https://doi.org/10.1213/ ane.0b013e31819d644c

16. Oliveira Junior JO, Freitas MF, Andrade CB, Chacur M, Ashmawi HA. Local analgesic effect of tramadol is mediated by opioid receptors in late postoperative pain after plantar incision in rats. J Pain Res. 2016;9:797-802. https://doi.org/10.2147/JPR.S117674 